\title{
Management of Benign and Malignant Pancreatic Duct Strictures
}

\author{
Enad Dawod and Michel Kahaleh \\ Division of Gastroenterology and Hepatology, New York Presbyterian Hospital, Weill Cornell Medical College, New York, NY, USA
}

The diagnosis and management of pancreatic strictures, whether malignant or benign, remain challenging. The last 2 decades have seen dramatic progress in terms of both advanced imaging and endoscopic therapy. While plastic stents remain the cornerstone of the treatment of benign strictures, the advent of fully covered metal stents has initiated a new wave of interest in calibrating the pancreatic duct with fewer sessions. In malignant disease, palliation remains the priority and further data are necessary before offering systematic pancreatic stenting. Clin Endosc 2018;51:156-160

Key Words: Pancreatic ducts; Pancreas; Fully covered metal stent; Cholangiopancreatography, endoscopic retrograde; Endosonography

\section{INTRODUCTION}

Pancreatic duct stricture is a common problem that is associated with various etiologies. Benign etiologies include chronic pancreatitis, recurrent acute pancreatitis, trauma, surgical complications, and pseudocysts. Pancreatic strictures can also be a manifestation of malignancy. ${ }^{1,2}$ The diagnosis and treatment of pancreatic strictures have proven challenging for physicians. Most pancreatic strictures present with persistent or recurrent abdominal pain, or with symptoms of chronic pancreatitis and exocrine insufficiency. The possibility of underlying malignancy necessitates investigation with high-quality cross-sectional imaging including computed tomography and magnetic resonance imaging/magnetic resonance cholangiopancreatography. Any masses that are appreciated on imaging should be followed by endoscopic ultrasonography with fine needle aspiration (EUS-FNA). ${ }^{3}$

EUS-FNA has replaced endoscopic retrograde cholan-

Received: May 30, 2017 Accepted: June 16, 2017

Correspondence: Michel Kahaleh

Division of Gastroenterology and Hepatology, New York Presbyterian Hospital, Weill Cornell Medical College, Cornell University, 1305 York Avenue, 4th Floor, New York, NY 10021, USA

Tel: +1-646-962-4000, Fax: +1-646-962-0110, E-mail: mkahaleh@gmail.com ORCID: http://orcid.org/0000-0003-0836-6114

(c) This is an Open Access article distributed under the terms of the Creative Commons Attribution Non-Commercial License (http://creativecommons.org/ licenses/by-nc/3.0) which permits unrestricted non-commercial use, distribution, and reproduction in any medium, provided the original work is properly cited. giopancreatography (ERCP) as the method of choice in obtaining tissue specimen, as it is associated with a higher success rate and fewer post-procedural complications. ${ }^{4}$ Pancreatic brushing should be employed in the absence of a definitive mass on imaging. ${ }^{3}$ Furthermore, repeat EUS has been shown to improve diagnostic yield in the case of continued suspicion of cancer and to increase the sensitivity of pancreatic mass detection in the setting of chronic pancreatitis. ${ }^{4,5}$ Confocal endomicroscopy is another technology that aids in diagnosing neoplasms in indeterminate masses and in the mapping of abnormal pancreatic ducts prior to surgery. ${ }^{6}$ Imaging and endoscopic diagnostic tests are ideally correlated with a careful evaluation of the patient's history to establish the benign or malignant nature of the pancreatic strictures. Serum markers such as IgG4 in autoimmune pancreatitis or CA 19-9 in pancreatic cancer can also be useful in determining the etiology of the stricture.

\section{TREATMENT}

The treatment of a pancreatic stricture depends on whether it is benign or malignant. Asymptomatic pancreatic strictures can be left without intervention if malignancy has been excluded. Persistent symptoms such as abdominal pain or postprandial pain are the indications for intervention in benign pancreatic strictures. Factors that must be considered 
when selecting the modality of treatment include the patient's individual characteristics such as age and comorbidities, the location and number of strictures, and finally, the expertise of the endoscopist in EUS and ERCP. Treatment of pancreatic strictures can be medical, endoscopic, or surgical. Medical treatment of pancreatic duct strictures includes abstinence from alcohol, strict adherence to a low-fat diet, small frequent meals, and pancreatic enzyme supplements to address symptoms of exocrine insufficiency. ${ }^{7}$

Rapid advancements in endoscopic technology have put endoscopy at the forefront of the management of pancreatic strictures. The mainstay of endoscopic therapy for pancreatic strictures includes pancreatic sphincterectomy, followed by the dilation of pancreatic stricture and the placement of a pancreatic duct stent (Fig. 1). This sequence is associated with immediate pain relief in $65 \%-95 \%$ of patients and with sustained pain relief in $32 \%-68 \%$ of patients. ${ }^{8,9} \mathrm{ERCP}$ is also considered the first-line modality in the management of main pancreatic duct obstruction in the setting of chronic pancreatitis. ${ }^{10,11} \mathrm{Di}-$ lation is usually done before stenting and can be performed using wire-guided balloons (4-6 mm), a bougie, or a Soehendra stent retriever. ${ }^{3}$ Plastic stents have become the standard endoscopic treatment of main pancreatic duct strictures in the setting of chronic pancreatitis and they are usually left in place for a fixed duration of time or exchanged upon recurrence of symptoms. ${ }^{12,13}$ In addition to plastic stents, self-expanding metal stents have also been successfully used in treating pancreatic strictures (Fig. 2); however, plastic stents are associated with more long-term follow-up data and experience. ${ }^{14}$ The larger diameter of plastic stents also seems to confer an advantage in terms of the rate of hospitalizations for abdominal pain. ${ }^{15} \mathrm{~A}$ high rate of stricture recurrence upon removal of the stent has been observed, with a $38 \%$ recurrence rate at the 2-year follow up and the need for repeat stenting. ${ }^{16}$ The number of strictures and the location of the stricture seem to be critical determining factors in the success of endotherapy. A symptomatic chronic pancreatitis patient with main pancreatic duct stricture at the head of the pancreas would be the ideal candidate for ERCP with stenting. Strictures at the tail of pancreas are more difficult to treat endoscopically. Moreover, endoscopic treatment of multiple chronic pancreatitis-related strictures (chain of lakes appearance) is even more challenging. ${ }^{17}$

The technical failure rates of ERCP range from 3\%-10\%. The most common reasons for technical failure include failure of cannulation of the main pancreatic duct, severe strictures, pancreatic stones, or altered anatomy. ${ }^{18-20}$ In patients where conventional ERCP failed, EUS-guided drainage of the main pancreatic duct is emerging as a less invasive alternative to surgery. Our team reported a large, international multicenter
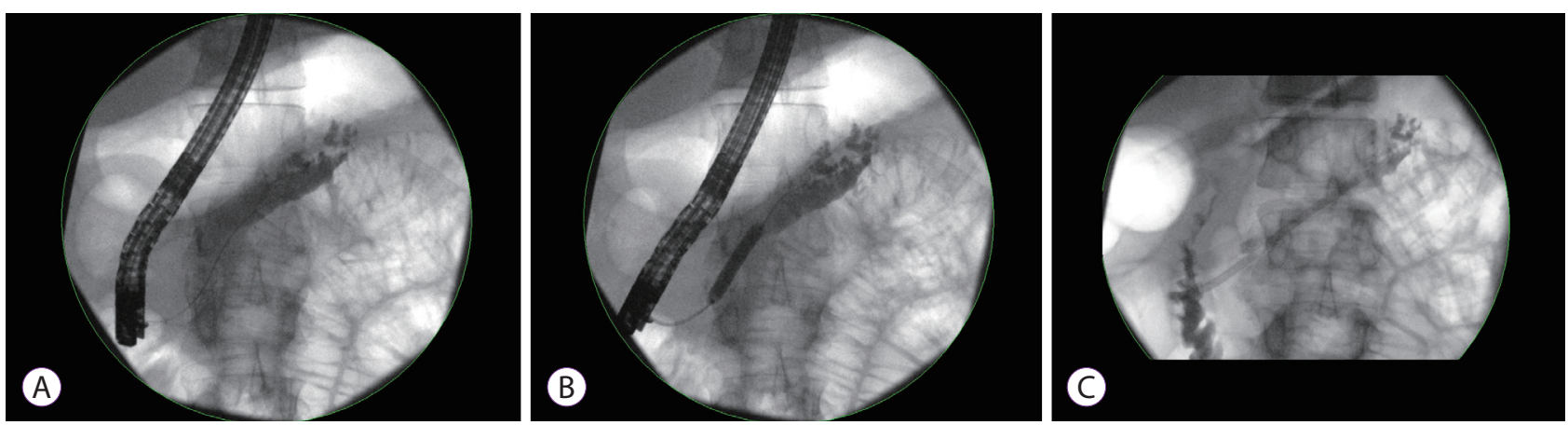

Fig. 1. The use of plastic stents in the treatment of benign pancreatic strictures. (A) Guidewire insertion. (B) Balloon dilation. (C) Plastic stent deployment.
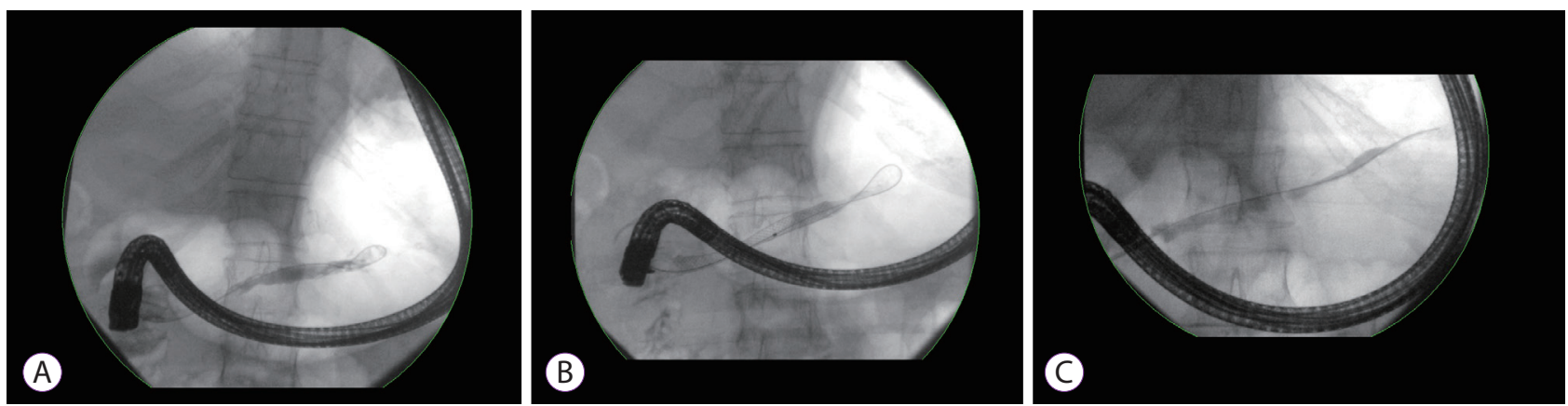

Fig. 2. The use of fully covered self-expanding metal stent (FCSMS) in treating benign pancreatic strictures. (A) Distal pancreatic stricture identified on fluoroscopy. (B) $8 \mathrm{~mm} \times 60$ FCSMS deployment. (C) Removal of the FCSMS at 3 months after deployment. Image showing stricture resolution on pressure injection. 
study on the safety and efficacy of EUS-guided pancreatic drainage (EUS-PD) in patients who failed conventional ERCP therapy for pancreatic strictures. Among a total of 80 patients, technical success was reported in $89 \%$ and clinical success was reported in $81 \%{ }^{21}$ Initial studies of EUS-PD have demonstrated a wide range of efficacy from $50 \%-100 \%,{ }^{18-20,22,23}$ which is likely reflective of the inherent learning curve. Conventionally, surgery or percutaneous intervention would be the next step for patients who fail ERCP therapy for pancreatic strictures; however, those approaches are both associated with significant morbidities. Our multicenter, international investigation demonstrated a $20 \%$ adverse events rate, which is still significantly lower than the $30 \%$ adverse events rate reported with surgical interventions. ${ }^{21,24-26}$

Pancreatic cancer is the fifth leading cause of cancer-related deaths in the western world. ${ }^{27}$ Pancreatic strictures and main pancreatic ductal obstructions are common manifestations of pancreatic malignancy. The vast majority of pancreatic cancer

Table 1. Data on the Use of Plastic Stents in the Treatment of Benign Pancreatic Strictures

\begin{tabular}{|c|c|c|c|c|c|c|c|}
\hline Author & Year & Type of stent & $\begin{array}{c}\text { Number of } \\
\text { patients }\end{array}$ & $\begin{array}{c}\text { Technical } \\
\text { success (\%) }\end{array}$ & $\begin{array}{c}\text { Immediate } \\
\text { clinical success }(\%)\end{array}$ & $\begin{array}{c}\text { Long-term } \\
\text { clinical success (\%) }\end{array}$ & $\begin{array}{c}\text { Follow-up } \\
\text { duration (mo) }\end{array}$ \\
\hline Cremer et al. ${ }^{32}$ & 1991 & Polyethylene & 75 & 98.6 & 94 & 52 & 37 \\
\hline Rösch et al. ${ }^{33}$ & 2002 & Various & 478 & 72 & N/A & 63 & 52 \\
\hline Vitale et al. ${ }^{34}$ & 2004 & Polyethylene & 89 & 100 & 83 & 63 & 43 \\
\hline Eleftherladis et al. ${ }^{16}$ & 2005 & Polyethylene & 100 & 100 & 100 & 70 & 69 \\
\hline Costamagna et al. ${ }^{10}$ & 2006 & $\begin{array}{l}\text { Polyethylene Am- } \\
\text { sterdam-type or } \\
\text { "Cremer" }\end{array}$ & 13 & 100 & 100 & 84 & 38 \\
\hline Weber et al. ${ }^{35}$ & 2007 & Polyethylene & 17 & 89.4 & 89 & 83 & 24 \\
\hline Sauer et al. ${ }^{15}$ & 2009 & Polyethylene & 163 & $\mathrm{~N} / \mathrm{A}$ & $\mathrm{N} / \mathrm{A}$ & 56 & 36 \\
\hline
\end{tabular}

N/A, not available.

Table 2. Data on the Use of FCSMS in the Treatment of Benign Pancreatic Strictures

\begin{tabular}{|c|c|c|c|c|c|c|c|c|}
\hline Author & Year & Type of FCSMS & $\begin{array}{l}\text { Number } \\
\text { of patients }\end{array}$ & $\begin{array}{l}\text { Technical } \\
\text { success } \\
(\%)\end{array}$ & $\begin{array}{c}\text { Clinical } \\
\text { success } \\
(\%)\end{array}$ & $\begin{array}{c}\text { Stent } \\
\text { placement } \\
\text { duration (mo) }\end{array}$ & Adverse events & $\begin{array}{c}\text { Follow-up } \\
\text { duration } \\
(\mathrm{mo})\end{array}$ \\
\hline Park et al. ${ }^{36}$ & 2008 & Niti-S D-type & 13 & 100 & 100 & 2 & $\begin{array}{l}\text { Stent migration }(n=5) \\
\text { Cholestasis }(n=2)\end{array}$ & 5 \\
\hline Sauer et al. ${ }^{37}$ & 2008 & VIABIL & 6 & 100 & 66 & 3 & None & 8 \\
\hline Moon et al. ${ }^{38}$ & 2010 & Niti-S bumpy type & 32 & 100 & 100 & 5 & $\begin{array}{l}\text { Stent-induced duct } \\
\text { change }(n=5) \\
\text { Mild acute pancreatitis } \\
(n=3)\end{array}$ & 20 \\
\hline Akbar et al. ${ }^{39}$ & 2012 & $\begin{array}{l}\text { VIABIL/ WallStent/ } \\
\text { WallFlex }\end{array}$ & 9 & 100 & 88.9 & 3.5 & $\begin{array}{l}\text { Stent migration }(n=1) \\
\text { Post-procedural } \\
\text { abdominal pain }(n=1)\end{array}$ & 18 \\
\hline $\begin{array}{l}\text { Giacino et } \\
\text { al. }^{40}\end{array}$ & 2012 & WallStent/WallFlex & 10 & 100 & 90 & $\mathrm{~N} / \mathrm{A}$ & $\begin{array}{l}\text { Post-procedural } \\
\text { abdominal pain }(n=3) \\
\text { Cholestasis }(n=2)\end{array}$ & 19.8 \\
\hline Landi et al. ${ }^{41}$ & 2016 & $\begin{array}{l}\text { Nitinol (bumpy } \\
\text { stent) }\end{array}$ & 15 & 100 & 54 & 6 & $\begin{array}{l}\text { Cholangitis }(n=2) \\
\text { Stent migration }(n=2)\end{array}$ & 18.5 \\
\hline Ogura et al. ${ }^{42}$ & 2016 & Niti-S biliary S-type & 13 & 100 & 92 & 5.7 & $\begin{array}{l}\text { Stent migration }(n=2) \\
\text { Post-procedural } \\
\text { abdominal pain }(n=1)\end{array}$ & 8.6 \\
\hline $\begin{array}{l}\text { Matsubara et } \\
\text { al. }^{43}\end{array}$ & 2016 & $\begin{array}{l}\text { Niti-S D-/bumpy } \\
\text { type }\end{array}$ & 10 & 100 & $70 \%$ & 3 & $\begin{array}{l}\text { Stent-induced duct } \\
\text { change }(n=2) \\
\text { Stent migration }(n=2)\end{array}$ & 35 \\
\hline
\end{tabular}

FCSMS, fully covered self-expanding metal stent; N/A, not available. 
patients are inoperable at the time of diagnosis and have a very poor prognosis; ${ }^{28}$ therefore, the main concern is palliation. As in the case of patients with chronic pancreatitis, endoscopic stenting can be used in the decompression of malignant ductal obstructions that cause postprandial epigastric pain in patients with pancreatic cancer, particularly in patients with tumors in the head of the pancreas. ${ }^{29}$ Both plastic and metal stents have been employed in the treatment of malignant pancreatic strictures. ${ }^{12}$ Plastic stents have a reported patency of 2 months, which is attributed to their small diameter. ${ }^{30}$ On the other hand, metal stents have demonstrated a longer duration of patency, fewer reinterventions, and increased cost-effectiveness in patients with a prognosis longer than 6 months. ${ }^{30,31}$ Whether metal or plastic stents provide better results remains to be determined, and further data are also needed to ascertain the efficacy of fully covered self-expanding metal stents in relieving malignant ductal obstructions. ${ }^{30}$ With both plastic and metal stents, technical success rates have ranged between $81 \%$ and $100 \%$, and rates of pain improvement have ranged between $61 \%$ and $100 \%{ }^{12}$

\section{CONCLUSIONS}

The diagnosis and treatment of pancreatic strictures can prove challenging, and a high index of suspicion should always be maintained in approaching patients with pancreatic strictures in order to rule out malignancy as the underlying etiology. High-quality imaging studies, patient history, and serum markers should be obtained in all patients, and the treatment modality of choice depends on the benign or malignant nature of the pancreatic stricture. Benign strictures can be left untreated if they are asymptomatic. Persistent abdominal pain and recurrent attacks of pancreatitis are among the indications for intervention. Patients in whom conventional ERCP endoscopic therapy for benign strictures fails should be offered EUS-PD as a safe, minimally invasive, and effective alternative to surgery, according to the availability of endoscopic expertise. Patients with malignant pancreatic strictures might benefit from palliation provided by the decompression of the pancreatic ductal obstruction, for which both plastic stents (Table 1) and metal stents (Table 2) have been used. ${ }^{10,15,16,32-43}$ However, more data and longer follow up periods are needed to establish the superiority of one type of stent over the other. Patients with benign strictures should be followed up in 3- or 6-month intervals if malignancy is suspected.

\section{Conflicts of Interest}

The authors have no financial conflicts of interest.

\section{REFERENCES}

1. Catalano MF. Endoscopic treatment of pancreatic duct strictures. Tech Gastrointest Endosc 1999;1:168-174.

2. Cohen SA, Siegel JH, Kasmin FE. Treatment of pancreatic strictures. Curr Treat Options Gastroenterol 2007;10:347-354.

3. Oza VM, Kahaleh M. Endoscopic management of chronic pancreatitis. World J Gastrointest Endosc 2013;5:19-28.

4. Eloubeidi MA, Varadarajulu S, Desai S, Wilcox CM. Value of repeat endoscopic ultrasound-guided fine needle aspiration for suspected pancreatic cancer. J Gastroenterol Hepatol 2008;23:567-570.

5. Varadarajulu S, Tamhane A, Eloubeidi MA. Yield of EUS-guided FNA of pancreatic masses in the presence or the absence of chronic pancreatitis. Gastrointest Endosc 2005;62:728-736; quiz 751, 753.

6. Kahaleh M, Turner BG, Bezak K, et al. Probe-based confocal LASER endomicroscopy (pCLE) in the pancreatic duct provides direct visualization of ductal structures and AIDS in clinical management. Gastrointest Endosc 2013;77(5 Suppl):AB165.

7. Warshaw AL, Banks PA, Fernández-Del Castillo C. AGA technical review: treatment of pain in chronic pancreatitis. Gastroenterology 1998;115:765-776.

8. Weber A, Schneider J, Neu B, et al. Endoscopic stent therapy in patients with chronic pancreatitis: a 5-year follow-up study. World J Gastroenterol 2013;19:715-720.

9. Talukdar R, Reddy DN. Pancreatic endotherapy for chronic pancreatitis. Gastrointest Endosc Clin N Am 2015;25:765-777.

10. Costamagna G, Bulajic M, Tringali A, et al. Multiple stenting of refractory pancreatic duct strictures in severe chronic pancreatitis: long-term results. Endoscopy 2006;38:254-259.

11. Dumonceau JM, Devière J, Le Moine O, et al. Endoscopic pancreatic drainage in chronic pancreatitis associated with ductal stones: long-term results. Gastrointest Endosc 1996;43:547-555.

12. Mangiavillano B, Pagano N, Baron TH, Luigiano C. Outcome of stenting in biliary and pancreatic benign and malignant diseases: a comprehensive review. World J Gastroenterol 2015;21:9038-9054.

13. Gupta R, Reddy DN. Stent selection for both biliary and pancreatic strictures caused by chronic pancreatitis: multiple plastic stents or metallic stents? J Hepatobiliary Pancreat Sci 2011;18:636-639.

14. Adler JM, Gardner TB. Endoscopic therapies for chronic pancreatitis. Dig Dis Sci 2017;62:1729-1737.

15. Sauer BG, Gurka MJ, Ellen K, Shami VM, Kahaleh M. Effect of pancreatic duct stent diameter on hospitalization in chronic pancreatitis: does size matter? Pancreas 2009;38:728-731.

16. Eleftherladis N, Dinu F, Delhaye M, et al. Long-term outcome after pancreatic stenting in severe chronic pancreatitis. Endoscopy 2005;37:223-230.

17. Tringali A, Boskoski I, Costamagna G. The role of endoscopy in the therapy of chronic pancreatitis. Best Pract Res Clin Gastroenterol 2008;22:145-165.

18. Tessier G, Bories E, Arvanitakis M, et al. EUS-guided pancreatogastrostomy and pancreatobulbostomy for the treatment of pain in patients with pancreatic ductal dilatation inaccessible for transpapillary endoscopic therapy. Gastrointest Endosc 2007;65:233-241.

19. François E, Kahaleh M, Giovannini M, Matos C, Devière J. EUS-guided pancreaticogastrostomy. Gastrointest Endosc 2002;56:128-133.

20. Brauer BC, Chen YK, Fukami N, Shah RJ. Single-operator EUS-guided cholangiopancreatography for difficult pancreaticobiliary access (with video). Gastrointest Endosc 2009;70:471-479.

21. Tyberg A, Sharaiha RZ, Kedia P, et al. EUS-guided pancreatic drainage for pancreatic strictures after failed ERCP: a multicenter international collaborative study. Gastrointest Endosc 2017;85:164-169.

22. Vila JJ, Pérez-Miranda M, Vazquez-Sequeiros E, et al. Initial experience with EUS-guided cholangiopancreatography for biliary and pancreatic duct drainage: a Spanish national survey. Gastrointest Endosc 2012;76:1133-1141. 
23. Fujii LL, Topazian MD, Abu Dayyeh BK, et al. EUS-guided pancreatic duct intervention: outcomes of a single tertiary-care referral center experience. Gastrointest Endosc 2013;78:854-864.e1.

24. Adams DB, Ford MC, Anderson MC. Outcome after lateral pancreaticojejunostomy for chronic pancreatitis. Ann Surg 1994;219:481-487; discussion 487-489.

25. Nealon WH, Thompson JC. Progressive loss of pancreatic function in chronic pancreatitis is delayed by main pancreatic duct decompression. A longitudinal prospective analysis of the modified puestow procedure. Ann Surg 1993;217:458-466; discussion 466-468.

26. Markowitz JS, Rattner DW, Warshaw AL. Failure of symptomatic relief after pancreaticojejunal decompression for chronic pancreatitis. Strategies for salvage. Arch Surg 1994;129:374-379; discussion 379-380.

27. DiMagno EP, Reber HA, Tempero MA. AGA technical review on the epidemiology, diagnosis, and treatment of pancreatic ductal adenocarcinoma. American gastroenterological association. Gastroenterology 1999;117:1464-1484.

28. Wehrmann T, Riphaus A, Frenz MB, Martchenko K, Stergiou N. Endoscopic pancreatic duct stenting for relief of pancreatic cancer pain. Eur J Gastroenterol Hepatol 2005;17:1395-1400.

29. Mekaroonkamol P, Willingham FF, Chawla S. Endoscopic management of pain in pancreatic cancer. JOP 2015;16:33-40.

30. Sharaiha RZ, Widmer J, Kahaleh M. Palliation of pancreatic ductal obstruction in pancreatic cancer. Gastrointest Endosc Clin N Am 2013;23:917-923.

31. Yeoh KG, Zimmerman MJ, Cunningham JT, Cotton PB. Comparative costs of metal versus plastic biliary stent strategies for malignant obstructive jaundice by decision analysis. Gastrointest Endosc 1999;49(4 Pt 1):466-471.

32. Cremer M, Devière J, Delhaye M, Baize M, Vandermeeren A. Stenting in severe chronic pancreatitis: results of medium-term follow-up in seventy-six patients. Endoscopy 1991;23:171-176

33. Rösch T, Daniel S, Scholz M, et al. Endoscopic treatment of chronic pancreatitis: a multicenter study of 1000 patients with long-term follow-up. Endoscopy 2002;34:765-771.
34. Vitale GC, Cothron K, Vitale EA, et al. Role of pancreatic duct stenting in the treatment of chronic pancreatitis. Surg Endosc 2004;18:1431-1434.

35. Weber A, Schneider J, Neu B, et al. Endoscopic stent therapy for patients with chronic pancreatitis: results from a prospective follow-up study. Pancreas 2007;34:287-294.

36. Park DH, Kim MH, Moon SH, Lee SS, Seo DW, Lee SK. Feasibility and safety of placement of a newly designed, fully covered self-expandable metal stent for refractory benign pancreatic ductal strictures: a pilot study (with video). Gastrointest Endosc 2008;68:1182-1189.

37. Sauer B, Talreja J, Ellen K, Ku J, Shami VM, Kahaleh M. Temporary placement of a fully covered self-expandable metal stent in the pancreatic duct for management of symptomatic refractory chronic pancreatitis: preliminary data (with videos). Gastrointest Endosc 2008;68:11731178

38. Moon SH, Kim MH, Park DH, et al. Modified fully covered self-expandable metal stents with antimigration features for benign pancreatic-duct strictures in advanced chronic pancreatitis, with a focus on the safety profile and reducing migration. Gastrointest Endosc 2010;72:8691

39. Akbar A, Baron TH. Covered self-expanding metal stent use in the pancreatic duct: a case series. Endoscopy 2012;44:869-873.

40. Giacino C, Grandval P, Laugier R. Fully covered self-expanding metal stents for refractory pancreatic duct strictures in chronic pancreatitis. Endoscopy 2012;44:874-877.

41. Landi R, Tringali A, Bove V, et al. Fully covered self-expandable metal stents to dilate pancreatic duct strictures due to chronic pancreatitis: a pilot study. Gastrointest Endosc 2016;83(5 Suppl):AB251-AB252.

42. Ogura T, Onda S, Takagi W, et al. Placement of a $6 \mathrm{~mm}$, fully covered metal stent for main pancreatic head duct stricture due to chronic pancreatitis: a pilot study (with video). Therap Adv Gastroenterol 2016;9:722-728.

43. Matsubara S, Sasahira N, Isayama $\mathrm{H}$, et al. Prospective pilot study of fully covered self-expandable metal stents for refractory benign pancreatic duct strictures: long-term outcomes. Endosc Int Open 2016;4:E1215-E1222. 